\title{
Geospatial Modeling for Investigating Spatial Pattern and Change Trend of Temperature and Rainfall
}

\author{
Md. Abu Syed ${ }^{1, *}$ and M. Al Amin ${ }^{2}$ \\ 1 Bangladesh Centre for Advanced Studies (BCAS), House 10, Road 16A, Gulshan 1, Dhaka 1212, Bangladesh \\ 2 Institute of Forestry and Environmental Sciences (IFES), Chittagong University, Chittagong 4331, \\ Bangladesh; prof.alamin@gmail.com \\ * Correspondence: mabusyed@gmail.com; Tel.: +88-0173-001-9213
}

Academic Editor: Christina Anagnostopoulou

Received: 5 February 2016; Accepted: 1 April 2016; Published: 11 April 2016

\begin{abstract}
Bangladesh has been experiencing increased temperature and change in precipitation regime, which might adversely affect the important ecosystems in the country differentially. The river flows and groundwater recharge over space and time are determined by changes in temperature, evaporation and crucially precipitation. These again have a spatio-temporal dimension. This geospatial modeling research aimed at investigating spatial patterns and changing trends of temperature and rainfall within the geographical boundary of Bangladesh. This would facilitate better understanding the change pattern and their probable impacts on the ecosystem. The southeastern region, which is one of the most important forest ecosystem zones in the country, is experiencing early onset and withdrawal of rain but increasing trends in total rainfall except in the Monsoon season. This means that the region is experiencing a lower number of rainy days. However, total rainfall has not changed significantly. The differential between maximum and minimum showed an increasing trend. This changing pattern in average max and min temperature along with precipitation might cause a situation in which the species that are growing now may shift to suitable habitats elsewhere in the future. Consequently, the biodiversity, watersheds and fisheries, productivity of land, agriculture and food security in the region will be affected by these observed changes in climate.
\end{abstract}

Keywords: climate change; GIS; geospatial modeling; geospatial pattern; precipitation; temperature; ecosystems; food security

\section{Introduction}

Bangladesh is the lowest riparian area in the Ganges, Brahmaputra and Meghna (GBM) River Basins. Nearly 93\% of the basin area lies outside Bangladesh in India, Nepal, Bhutan and China [1]. The climate in Bangladesh is mostly governed by its geographical location in the mouth of the Bay of Bengal and the deltaic flood plain in the foot hill of the Himalayas [2]. Ocean circulations in the Indian Ocean, Bay of Bengal and the Tropical Channel have great influence on Bangladesh climate. Bangladesh has a humid, warm, tropical climate. Its climate is influenced primarily by the Monsoon and partly by Pre-Monsoon and Post-Monsoon circulations. The southwest Monsoon originates over the Indian Ocean and carries warm, moist, and unstable air [3]. The Monsoon has its onset during the first week of June and ends in the first week of October, with some inter-annual variability in dates. Besides the Monsoon, the easterly trade winds are also active, providing warm and relatively drier circulation. In Bangladesh, there are four prominent seasons, namely, Winter (December to February), Pre-Monsoon (March to May), Monsoon (June to August), Post-Monsoon (September to November).

The Germanwatch Long-Term Climate Risk Index (CRI) 2011 has identified Bangladesh as the country most affected by extreme climate events during 1990-2009 [4]. Many projected climate change (CC) impacts including sea level rise, higher temperatures, erratic Monsoon precipitation and run-off, 
potentially reduced dry season precipitation, and increase in cyclone frequency and intensity would in fact reinforce many other baseline stresses that already pose a serious impediment to the economic development of Bangladesh. In the past, a number of studies were carried out on trends in climate parameters over Bangladesh and South Asia [5]. Chowdhury and Debsharma [6] and Mia [7] pointed out that temperature has been changed (by analyzing historical data of some selected meteorological stations). References $[8,9]$ reported that mean annual temperatures of Bangladesh have increased during the period of $1895-1980$ at $0.31^{\circ} \mathrm{C}$ over the past two decades. Karmakar and Shrestha [10] using the 1961-1990 data for Bangladesh have projected that annual mean maximum temperature would increase to $0.4^{\circ} \mathrm{C}$ and $0.73^{\circ} \mathrm{C}$ by the year of 2050 and 2100, respectively. In terms of precipitation, most models show increased annual precipitation for Bangladesh. Some models also showed the possibility of increasing Monsoon precipitation (May to September), and decreasing dry season precipitation (December to February). The mean annual rainfall is about $2320 \mathrm{~mm}$, but there are places with a mean annual rainfall of $6000 \mathrm{~mm}$ or more [11]. A long duration of heavy rainfall associated with "norwester" thunderstorms is very common in Bangladesh [11,12]. More than $80 \%$ of the $2,300 \mathrm{~mm}$ of annual precipitation that falls on Bangladesh comes during the Monsoon period [13]. Annual rainfall ranges from $1200 \mathrm{~mm}$ in the extreme west to over $5000 \mathrm{~mm}$ in the east and northeast [14]. Changes in the distribution of river flows and groundwater recharge over space and time are determined by changes in temperature, evaporation and, crucially, precipitation [15]. Some CC impacts on hydrological processes have been observed already $[16,17]$, and further changes are projected. This geospatial research aimed at investigating spatial patterns and changing trends of temperature and rainfall within the geographical boundary of Bangladesh and the interlinkage between them. This would facilitate better understanding of changing patterns, and their probable impacts on the ecosystem that were discussed in another author's paper [18] and a book chapter [19].

In short, geospatial is a methodology or set of analytical procedures used to derive information about spatial relationships among geographic phenomena. In most cases, geospatial models are two-dimensional, which take parameters on time and space to simulate a process and visualize a phenomena at given time and space. The evaluation of high resolution Regional Climate Models (RCMs) is seriously constrained by the lack of representative high-resolution observational datasets [18]. Gaps in well distributed and quality datasets on climate parameters are also big challenges in carrying out dynamical three-dimensional experiments covering Bangladesh. It is also important to keep in mind that, while horizontal resolution is readily increased down to about $10 \mathrm{~km}$, real vertical resolution in the surface layers is more a function of the boundary layer scheme than of numbers, which makes the computational time and resources prohibitively high. This study utilized geospatial techniques and tools for generating national to landscape level high-resolution geospatial scenarios of climate parameters.

\section{Materials and Methods}

\subsection{Materials}

Maximum and minimum monthly temperature and rainfall observation data from 34 meteorological stations of BMD (Bangladesh Meteorological Department) located all over Bangladesh were collected from the BMD database for a thirty-year period of 1978-2007 for this study. For data analysis spreadsheet packages of MS Excel and SPSS (Statistical Package for Social Science) were used, whereas ArcGIS 10.1 was used for geo-spatial analysis. A Spatial Analysis Tool in the ArcGIS 10.1 package was used for investigating spatial patterns in data.

\subsection{Study Area}

Bangladesh is located between $20^{\circ}$ to $26^{\circ} \mathrm{N}$ and $88^{\circ}$ to $92^{\circ} \mathrm{E}$. It is bordered on the west, north and east by India, on the southeast by Myanmar, and on the south by the Bay of Bengal. The northern most area of the country is a few kilometers south of the Himalayans, which has profound influence on 
the climate in Bangladesh. Most of the country is low-lying land comprising mainly the delta of the Ganges and Brahmaputra rivers. Floodplains occupy $80 \%$ of the country. Mean elevations range from less than 1 meter on tidal floodplains, 1 to 3 meters on the main river and estuarine floodplains, and up to 6 meters in the Sylhet basin in the northeast [19]. Only in the extreme northwest are elevations greater than 30 meters above the mean sea level. The northeast and southeast parts of the country are undulating and hilly (compared to the mostly deltaic floodplain), with some tertiary hills over 1000 meters above mean sea level [20]. These two regions are historically home to the country's terrestrial tropical forest ecosystems.

\subsection{Methodology}

Figure 1 presents conceptual and sequential analytical process flows of research. It is important to note that this paper is part of a larger piece of research and only the geospatial modeling part of the research is presented here.

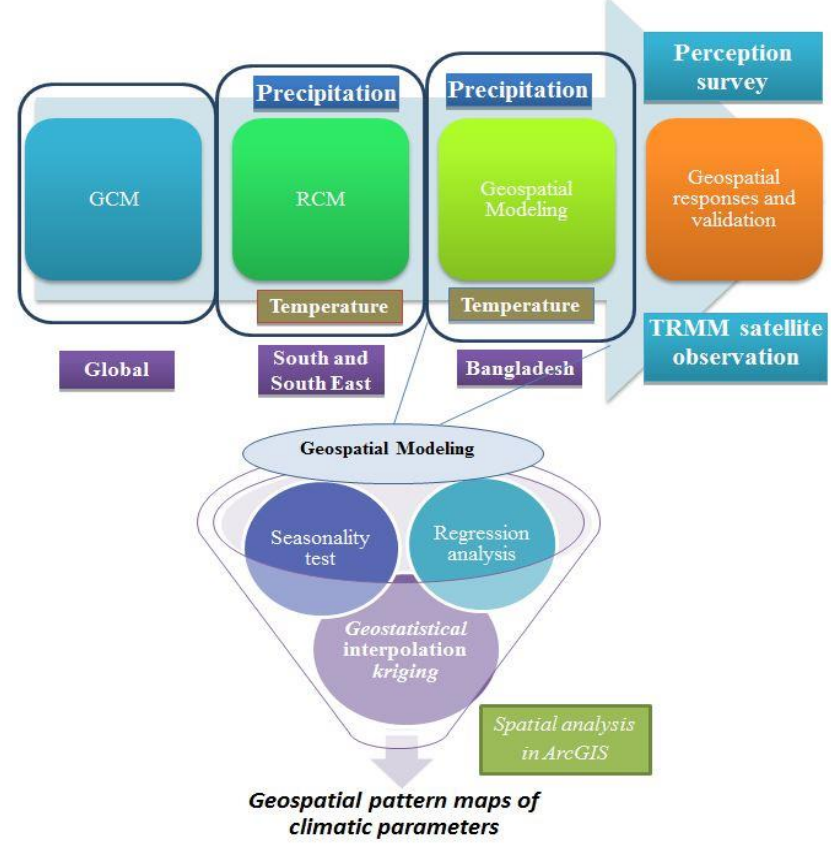

Figure 1. Schematic diagram shows the conceptual framework and sequential process of the research.

\subsubsection{Regression Model}

Regression analysis is widely used for prediction and forecasting, where its use has substantial overlap with the field of machine learning. Regression analysis is also used to understand which among the independent variables are related to the dependent variable, and to explore the forms of these relationships. In restricted circumstances, regression analysis can be used to infer causal relationships between the independent and dependent variables. However this can lead to illusions or false relationships, so caution is advisable [21].

In statistics, regression analysis includes many techniques for and analyzing several variables in discerning the relationship between a dependent variable and one or more independent variables. It helps one understand how the value of the dependent variable changes when any one of the independent variables is varied, while the other independent variables are held fixed.

A large body of techniques for carrying out regression analysis has been developed. Familiar methods such as linear regression and ordinary least squares regression are parametric, in that the regression function is defined in terms of a finite number of unknown parameters that are estimated 
from the data. Nonparametric regression refers to techniques that allow the regression function to lie in a specified set of functions, which may be infinite-dimensional.

The performance of regression analysis methods in practice depends on the form of the data generating process, and how it relates to the regression approach being used. Since the true form of the data-generating process is generally not known, regression analysis often depends to some extent on making assumptions about this process. These assumptions are sometimes testable if a large amount of data is available. Regression models for prediction are often useful even when the assumptions are moderately violated, although they may not perform optimally. However, in many applications, especially with small effects or questions of causality based on observational data, regression methods give misleading results [22,23].

\subsubsection{Mann Kendall Test}

Mann-Kendall tests are non-parametric tests for detection of trend in a time series. These tests are widely used in environmental science because they are simple, robust and can cope with missing values and values below a detection limit. Since the first proposals of the test by [24,25], covariance between Mann-Kendall statistics were proposed by [26] and the test was extended in order to include seasonality [27], multiple monitoring sites [28] and covariates representing natural fluctuations [29]. The present program (MS Excel and it's Add in XLSTAT) has incorporated all of these features.

By the Mann-Kendall test, this study tested the null hypothesis ( $\mathrm{H} 0)$ of no trend, i.e., the observations $x_{i}$ are randomly ordered in time, against the alternative hypothesis (H1), where there is an increasing or decreasing monotonic trend. The data values were evaluated as an ordered time series. Each data value was compared with all subsequent data values. If a data value from a later time period was higher than a data value from an earlier time period, the statistic $S$ is incremented by 1 . On the other hand, if the data value from a later time period was found to be lower than a data value sampled earlier, $\mathrm{S}$ had been decremented by 1 . The net result of all such increments and decrements yields the final value of $\mathrm{S}[28]$. The $\mathrm{M}-\mathrm{K}$ test statistic $\mathrm{S}$ is calculated using the formula:

$$
\begin{gathered}
S=\sum_{k-1}^{n-1} \sum_{j-k+1}^{n} \operatorname{Sin}\left(x_{j}-x_{k}\right), \\
\operatorname{Sin}\left(x_{j}-x_{k}\right)=\left\{\begin{array}{c}
+1 \text { if }\left(x_{j}-x_{k}\right)>0 \\
0 \text { if }\left(x_{j}-x_{k}\right) \geqslant 0 \\
-1 \text { if }\left(x_{j}-x_{k}\right)>0
\end{array},\right.
\end{gathered}
$$

where $x_{j}$ and $x_{k}$ are the annual values in years $j$ and $k, j>k$, respectively.

If $\mathrm{n}<10$, the value of $|\mathrm{S}|$ was compared directly to the theoretical distribution of $S$ derived by Mann and Kendall [30]. The two-tailed test was used. At a certain probability level, H0 is rejected in favor of $\mathrm{H} 1$ if the absolute value of $S$ equals or exceeds a specified value $S \alpha / 2$, where $S \alpha / 2$ is the smallest $S$, which has a probability less than $\alpha / 2$ to appear in case of no trend. A positive (negative) value of $S$ indicates an upward (downward) trend [31,32]. For $n \geqslant 10$, the statistic $S$ is approximately normally distributed with the mean and variance.

\subsubsection{Mathematical Interpolation Methods}

The geostatistical interpolation technique kriging was used because of its robustness in meteorological data applications (trend surface analysis, inverse distance weighting) or for their perceived advantages for climatic and phonological interpolations at a variety of spatial and temporal scales (ordinary kriging, partial thin plate splines). This method produces interpolation values by relying on an unknown mean value, allowing local influences due to nearby neighboring values (Figure 2). When the mean is unknown, there are few assumptions. This makes ordinary kriging particularly flexible. Temperature/Rainfall trends for all the weather stations were analyzed based 
on 30 years (1978-2007) of observation. To make a continuous scenario for the whole country, data interpolation was carried out in two steps.

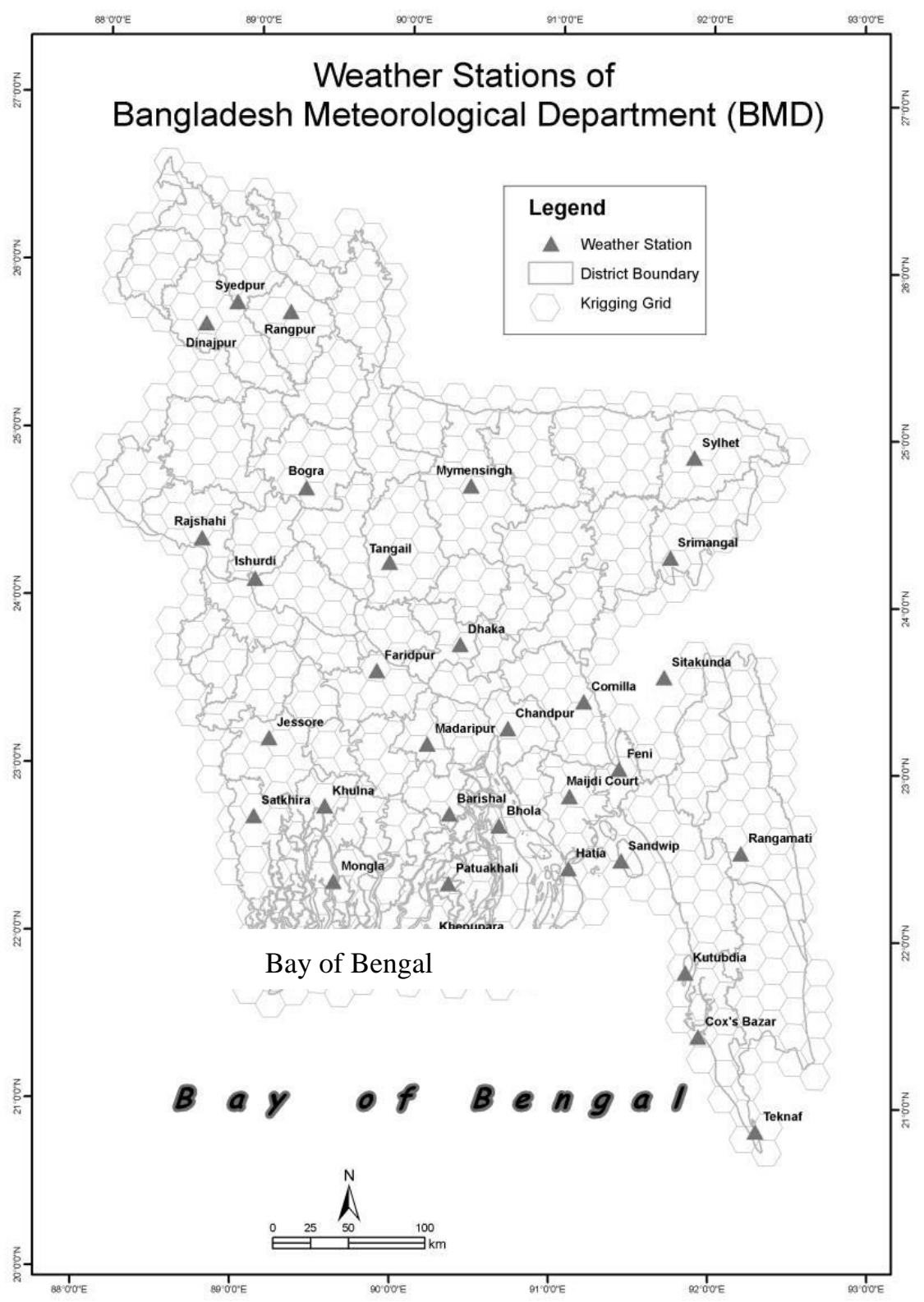

Figure 2. Geostatistical Kriging Mess for interpolation of missing values for the study area.

Step 1

Tessellated the whole study area into equal hexagons of $1200 \mathrm{sq} . \mathrm{km}$. Imported a value (Temperature/Rainfall Trend) for all the hexagons from the nearest (Arial Distance) weather station using Spatial Joint Tool in ArcGIS.

Step 2

In the second step, the Kriging Geostatistical Technique was used to interpolate (Figure 2) the values using the Spatial Analyst tool in ArcGIS.

Among the 34 stations, four stations with unique climatic conditions were selected as representatives of the whole country for detailed analysis purposes. For regional study of temperature variability, Rajshahi, Barisal, Chittagong and Sylhet meteorological stations were selected as 
representatives of their own regional climatic conditions. Rajshahi is in the drought prone northwest region of Bangladesh. Barisal, the coastal flood plain is in the southwest while Chittagong is in the southeast hilly coastal region and Sylhet is in the northeast region (foot hills of Meghalaya hill range) region of Bangladesh. The whole year was sub-grouped into four seasons (i) Pre-Monsoon (March, April and May (MAM)), (ii) Monsoon (June, July and August (JJA)), (iii) Post-Monsoon (September, October and November (SON)) and (iv) Winter (December, January and February (DJF)). Trend analysis has been conducted on seasonal average data for all the stations. A basic linear regression model was adopted to analyze time trend and interrelation between temperature and rainfall using SPSS. The findings on trends in temperature and rainfall from 34 stations were then spread within the whole country to make a continuous scenario interactively using Geostatistical Kriging Technique and Spatial Analyst tools in the ArcGIS platform.

Patterns of meteorological parameters such as temperature and rainfall are greatly influenced by global as well as regional geography e.g., presence of mountain, distance from sea and location in relation to the sea. In climate or meteorological data analysis, spatial distribution and pattern bear utmost importance because many other environmental variables [33] that govern ecosystems and their services depend on climate [34].

Geostatistics, which is based on the theory of regionalized variables, is increasingly preferred by the scientific community because it allows for capitalizing on the spatial correlation among neighboring observations to predict attribute values at unsampled locations [35]. Geostatistical methods have been shown to be superior to other interpolation/extrapolation methods, such as Thiessen polygon, polynomial interpolation, and inverse distance methods [36,37]. One of the important advantages of the geostatistical method is to use additional information.

\subsubsection{Kriging-Stochastic/Deterministic Interpolation}

Stochastic methods are ones that incorporate randomness. The imaginary interpolated surface is conceptualized as one of many that might have been observed, all of which could have produced the known data points. Kriging interpolation procedures produce trend surface analysis that allows the statistical significance of the surface and uncertainty of the predicted value to be calculated. Daily weather conditions are known to influence the growth and development of many biological organisms. It is therefore surprising that relatively few ecological or environmental studies focus upon the interpolation of continuous national coverage of daily temperature using now well-developed geostatistical or splining techniques (e.g., [38]).

It has been postulated that the actual interpolation algorithm used is less critical than the incorporation of environmentally determined gridded variables to augment the interpolation procedure $[39,40]$, although multiple guiding variables are rarely used in either applied studies or research comparing interpolator performance in studies at a daily time step. Certainly, as reported by Jarvis and Stuart [41], this issue, both [42] and [38] are able to relate patterns of uncertainty in their interpolated temperature surfaces with environmental influences such as proximity to the coast or urban heat islands.

Their conclusions suggest that polynomial regression (trend surface plus covariates) is preferable to other local techniques such as inverse distance weighting. In a study of greater depth for the same area [42], second-degree trend models (including Kriging with External Drift (KED) is a non-stationary geostatistical method. Here, we focus on the use of secondary information from a model to obtain better prediction.

In the case of KED, predictions at new locations are made by:

$$
\mathrm{Z}_{\mathrm{KED}}=\left(\mathrm{S}_{0} \sum_{\mathrm{i}=1}^{\mathrm{n}} \mathrm{w}_{\mathrm{i}}^{\mathrm{KED}}\left(\mathrm{S}_{0}\right) * \mathrm{z}\left(\mathrm{S}_{\mathrm{i}}\right)\right.
$$


for

$$
\sum_{\mathrm{i}=1}^{\mathrm{n}} \mathrm{w}_{\mathrm{i}}^{\mathrm{KED}}\left(\mathrm{S}_{0}\right) * \mathrm{qk}\left(\mathrm{S}_{\mathrm{i}}\right)=\mathrm{q}_{\mathrm{k}}\left(\mathrm{S}_{0}\right) ; \mathrm{k}=1, \ldots, \quad \mathrm{p}
$$

where $\mathrm{z}$ is the target variable, $\mathrm{q}_{\mathrm{k}} \mathrm{s}$ are the predictor variables, i.e., values at new location $\left(\mathrm{S}_{0}\right), \partial_{0}$ is the vector of KED weights $\left(w_{i}^{K E D}\right), P$ is the number of predictors and $z$ is the vector of $n$ observations at primary locations, [43] External drift kriging algorithm is explained in-depth, which has been used in this study.

\section{Results}

\subsection{Changing Trends of Seasonal Maximum and Minimum Temperature}

The observed climatic data from 1978 to 2007 indicate that the average temperature in Bangladesh is increasing for all the four seasons. In Pre-Monsoon (March-May), average maximum and minimum temperature (Figures 3-5) were found to be increasing at a rate of $0.016{ }^{\circ} \mathrm{C}$ and $0.015{ }^{\circ} \mathrm{C}$ per year, respectively. Similarly, the rate of increase in the average maximum and minimum were found to be $0.034{ }^{\circ} \mathrm{C}$ and $0.014{ }^{\circ} \mathrm{C}$ for Monsoon (June-August), $0.018^{\circ} \mathrm{C}$ and $0.010{ }^{\circ} \mathrm{C}$ for Post-Monsoon (September-November) and $0.015{ }^{\circ} \mathrm{C}$ and $0.009{ }^{\circ} \mathrm{C}$ for Winter (December-February).

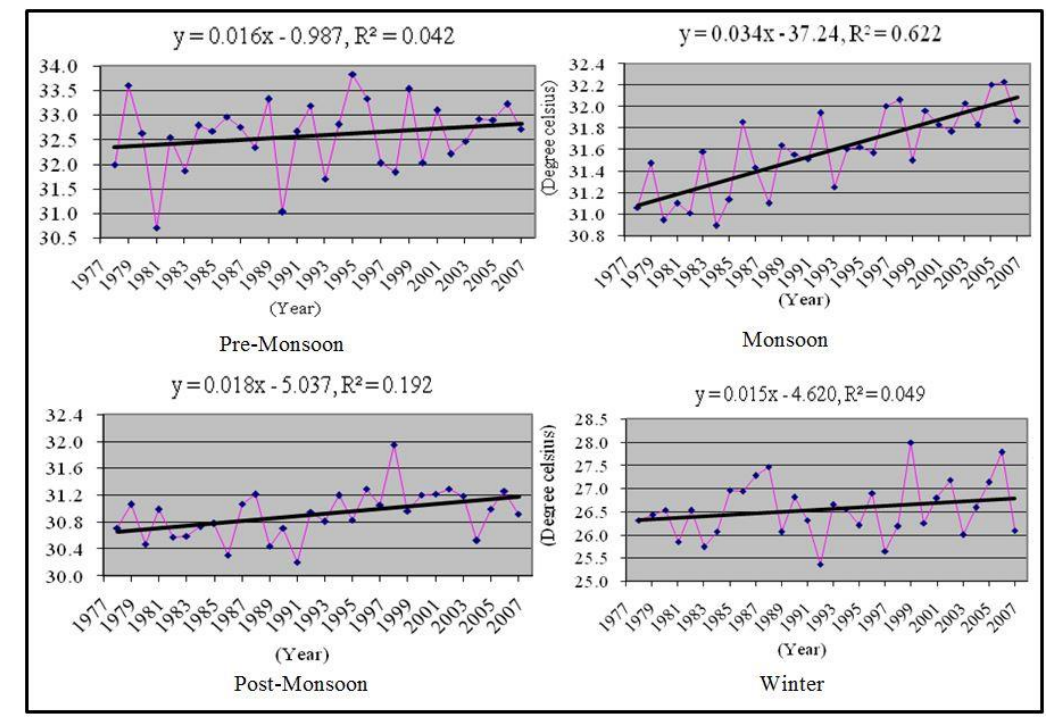

Figure 3. Annual mean maximum temperature for period 1978-2007.

It was also revealed that 2006 was the warmest year and 1984 was the coldest year in the last 30 years with a yearly average temperature of $31.1^{\circ} \mathrm{C}$ and $20.7^{\circ} \mathrm{C}$. Among the last 30 years, Bangladesh experienced the warmest Pre-Monsoon in 1995 (seasonal average $33.8^{\circ} \mathrm{C}$ ) and the coldest Winter in the year 1989 (seasonal average $13.1^{\circ} \mathrm{C}$ ). Reference [10] has studied surface climatological data on monthly and annual mean maximum and minimum temperature, and monthly and annual rainfall for the period of 1961-1990. The study showed an increasing trend of mean maximum and minimum temperature in some seasons and a decreasing trend in some others. The overall trend of the annual mean maximum temperature has shown a significant increase over the period of 1961-1990. Regional variations have been observed around the average trend [7].

Observed data of the Rajshahi Station (from 1978 to 2007) (Figures 4 and 5) indicate that overall annual maximum and minimum temperature are increasing at the rate of $0.008{ }^{\circ} \mathrm{C}$ and $0.003{ }^{\circ} \mathrm{C}$, respectively. 


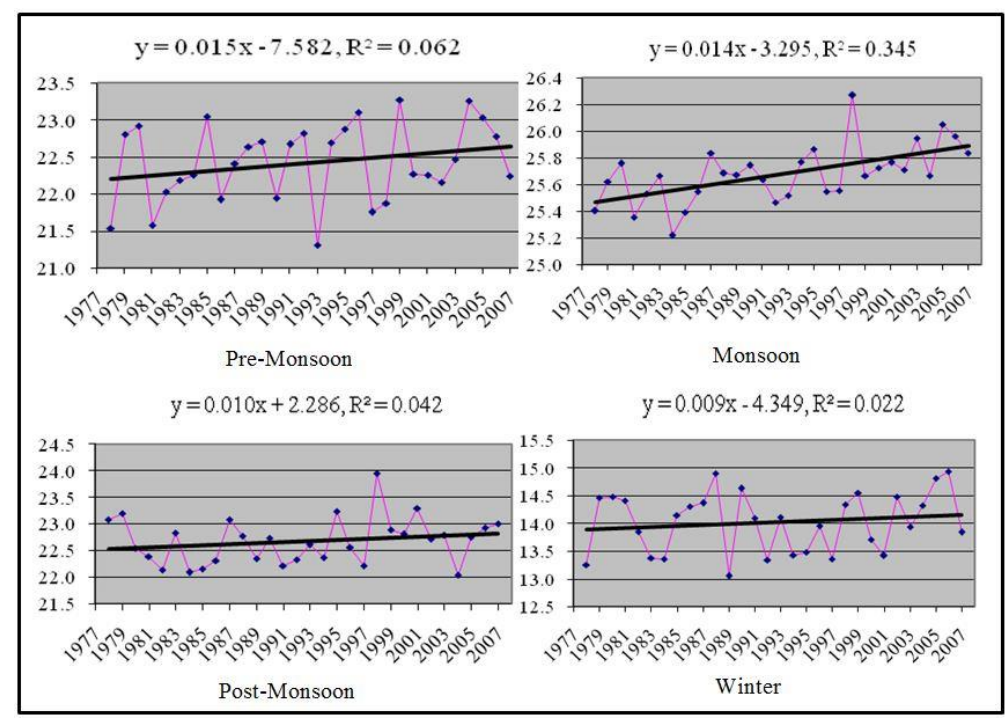

Figure 4. Average mean annual minimum temperature in different seasons.

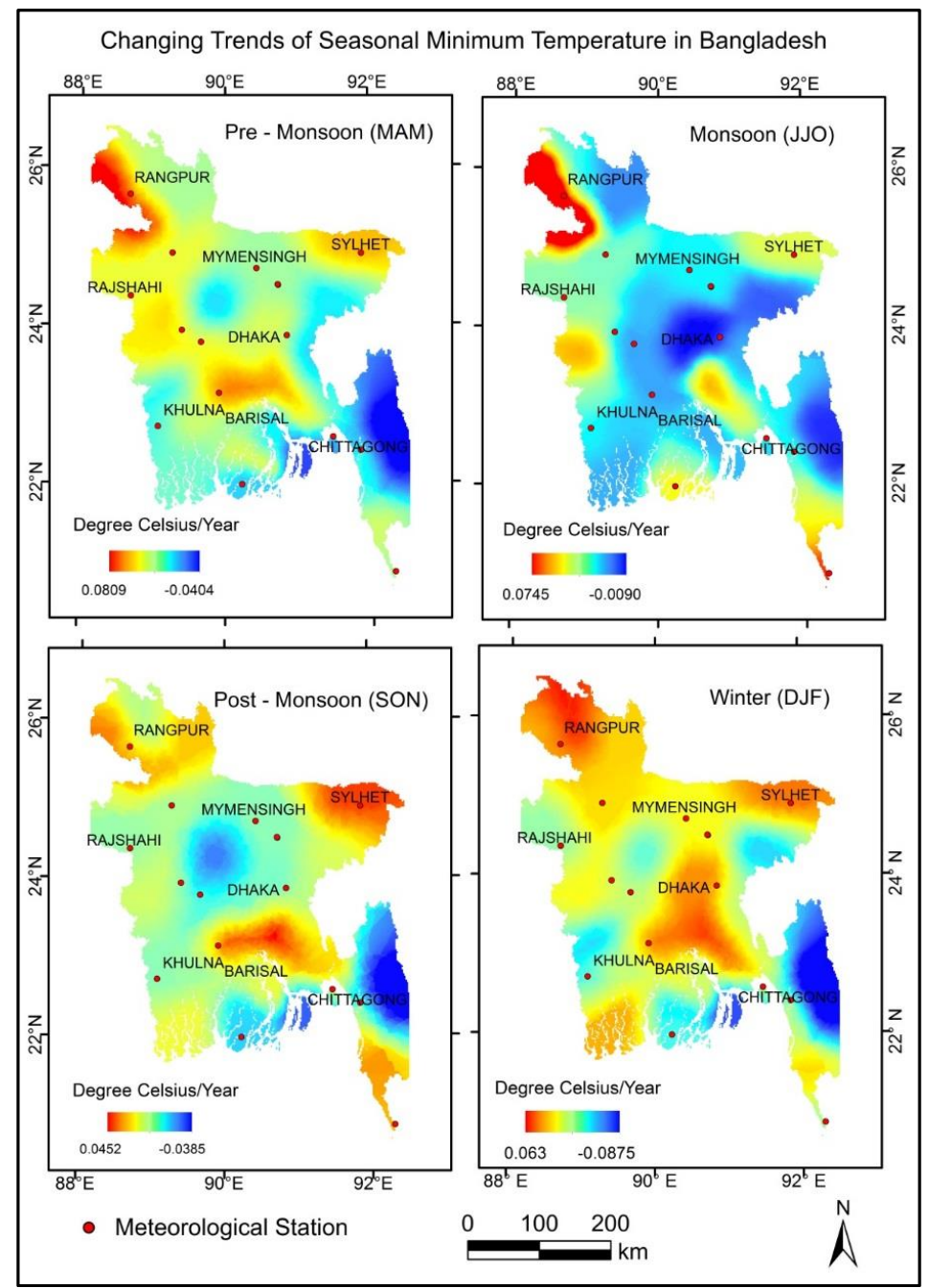

Figure 5. Geospatial distribution changing tends at seasonal average minimum temperature. 
However, rate of change in the Monsoon season is much higher than annual rate of change. The average maximum temperature in the Pre-Monsoon season in Rajshahi exhibited an increasing trend while (Figure 4) Average Maximum Temperature in Pre-Monsoon (Bangladesh) decreasing trend at a rate of $0.014{ }^{\circ} \mathrm{C}$ per year. This decreasing trend also prevailed for the average maximum temperature of the Post-Monsoon in the region. In Monsoon season (June, July and August), the average maximum and minimum temperature show an increasing trend annually at the rate of $0.032{ }^{\circ} \mathrm{C}$ and $0.013{ }^{\circ} \mathrm{C}$, respectively, which means Monsoon season is becoming warmer. On the other hand, average minimum temperature in Winter season (December, January and February) shows almost no change $\left(0.004{ }^{\circ} \mathrm{C}\right.$ /year) while maximum temperature shows a slight increasing trend annually at the rate of $0.010^{\circ} \mathrm{C}$ (Figure 3).

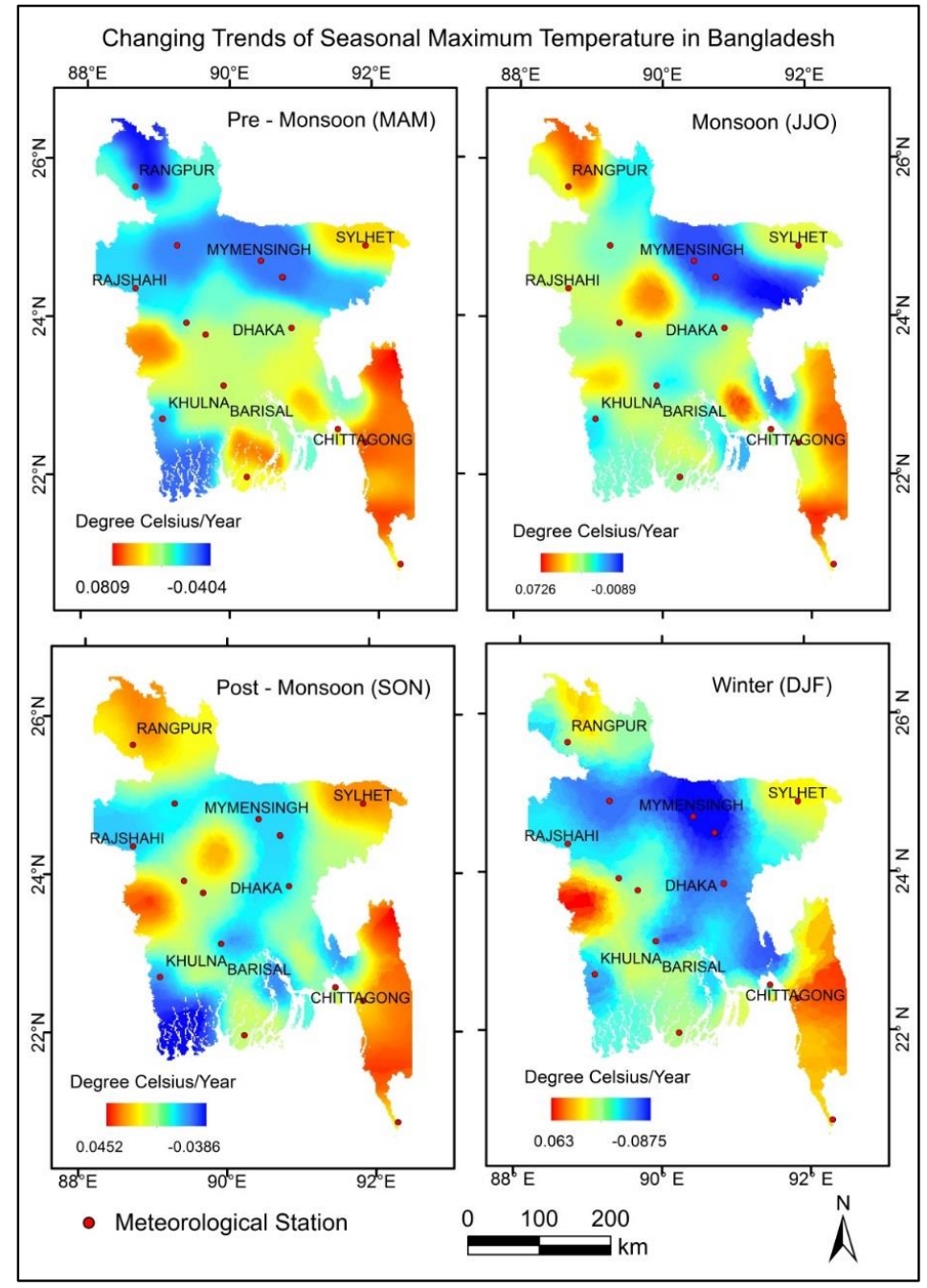

Figure 6. Geospatial distribution changing tends in seasonal average maximum temperature.

Observations from Barisal meteorological station revealed both maximum and minimum average temperature in this region increasing annually (Figures 4 and 5). This region experienced comparatively hotter Monsoon and Winter seasons than in the past. The highest rate, $0.030^{\circ} \mathrm{C} /$ year was recorded from 1978 to 2007 observations (30 years) for the average maximum temperature in the Monsoon season with a similar increasing rate in Winter $0.026^{\circ} \mathrm{C}$ /year and $0.027^{\circ} \mathrm{C} /$ year for average maximum and minimum temperature, respectively

In Chittagong, the increasing trend in temperature is much higher than the other regions of Bangladesh. In Pre-Monsoon, the increase rate is $0.049{ }^{\circ} \mathrm{C} /$ year and $0.038{ }^{\circ} \mathrm{C} /$ year for average 
maximum and minimum temperature, respectively. In Monsoon and Post-Monsoon, the rate of increase rate is relatively lower than Pre-Monsoon and Winter season. The Winter season of Chittagong is getting warmer at a rate of $0.040^{\circ} \mathrm{C} /$ year. The average maximum temperature is increasing at a rate of $0.067^{\circ} \mathrm{C} /$ year and the average minimum temperature is increasing at $0.031^{\circ} \mathrm{C} /$ year. During the last 30 years, the highest average maximum temperature in Winter was $29.1^{\circ} \mathrm{C}$ in the year 2002 , and the lowest average minimum temperature was $10^{\circ} \mathrm{C}$ in the year 1989 .

Sylhet, the northeast region of Bangladesh is also experiencing the impact of global warming all year round. The increasing trend in temperature is a comparatively higher $\left(0.061{ }^{\circ} \mathrm{C} /\right.$ year $)$ average minimum temperature in Winter season. The remaining observations exhibited a similar warming trend $\left(0.031{ }^{\circ} \mathrm{C} /\right.$ year to $0.05{ }^{\circ} \mathrm{C}$ /year $)$ with little exception in average minimum temperature in the Monsoon $\left(0.02{ }^{\circ} \mathrm{C} /\right.$ year $)$.

All four regions of Bangladesh (Rajshahi, Barisal, Chittagong and Sylhet) recorded a positive trend in temperature over the past 30 years (1978-2008) of observations except little decrease in average maximum temperature in Pre- and Post-Monsoon seasons in the Rajshahi region (Figures 5-7). The past 30 years of observations showed that average temperature is increasing comparatively sharply in the Chittagong and Sylhet regions in comparison with the Barisal and Rajshahi regions. On average, the temperature increase rate in Winter is much more rapid than other seasons in Bangladesh.

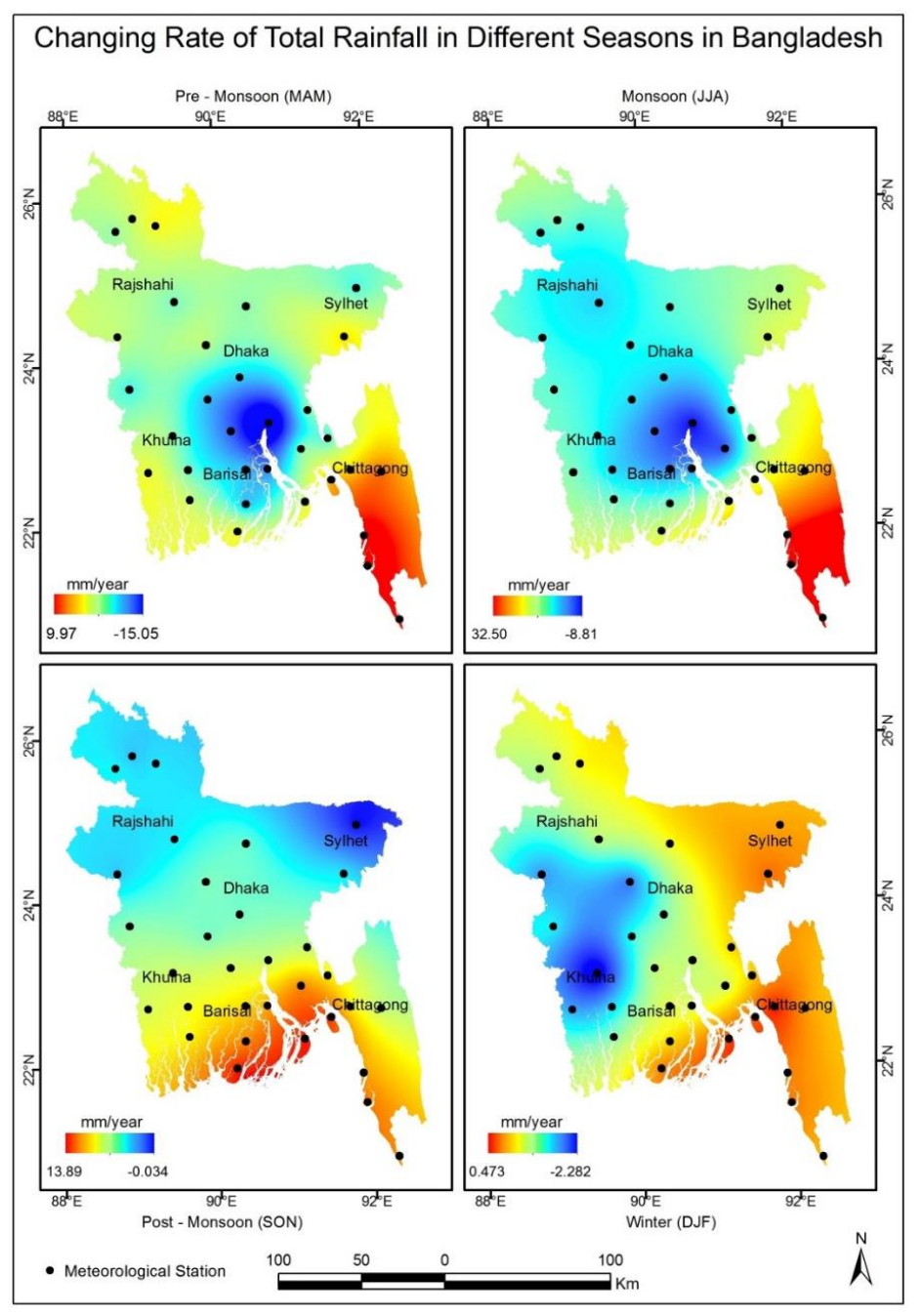

Figure 7. Geospatial distribution of changing trends in seasonal average rainfall. 


\subsection{Changing Trends in Total and Monthly Average Rainfall}

Bangladesh has a subtropical monsoon climate characterized by wide seasonal variations in rainfall. Bangladesh gets maximum rainfall in the monsoon season and minimum rainfall in the dry and cool Winter. The past 30 years (1978-2007) of observations showed that the mean rainfall during the Monsoon is about $1391 \pm 189 \mathrm{~mm}$ having maximum rainfall $1808 \mathrm{~mm}$ in 1984 and $1076 \mathrm{~mm}$ in 1992. In Winter, maximum rainfall was recorded as $93 \mathrm{~mm}$ in 1981 with a minimum about $3 \mathrm{~mm}$ in 2004. Recorded rainfall data revealed that average rainfall in Bangladesh is increasing at a rate of $3.346 \mathrm{~mm} /$ year in Monsoon and $8.084 \mathrm{~mm} /$ year in Post-Monsoon. In Winter and the Pre-Monsoon, average rainfall trend is negative.

In Rajshahi, the rainfall pattern for the last 30 years was similar in Pre-Monsoon, Monsoon and Post-Monsoon seasons. In Winter season, rainfall is showing a negative trend $(-1.85 \mathrm{~mm}$ /year). The Rajshahi meteorology station recorded an average of $1510 \pm 306 \mathrm{~mm}$ rainfall per year. In 1981, this region received $2241 \mathrm{~mm}$ (maximum) and $843 \mathrm{~mm}$ (minimum) in 1992.

Rainfall records from Barisal illustrated that the total rainfall is decreasing in Pre-Monsoon $(-3.978 \mathrm{~mm} /$ year) (Figure 8a), Monsoon (-7.0049 mm/year) (Figure 8b) and in Winter $(-0.3519 \mathrm{~mm} /$ year) (Figure 9b). In the Post-Monsoon, rainfall is found to be increasing at a rate of $8.6912 \mathrm{~mm} /$ year (Figures 8 and 9). Chittagong, the hilly coastal region of Bangladesh, is experiencing an increasing trend in total rainfall except in the Monsoon season. It may be due to shifting of Monsoon onset/withdrawal periods of this region (need detailed study). Among the considered last 30 years observations, monsoon in Chittagong got the highest rainfall $(2878 \mathrm{~mm})$ in 1983 and the lowest $(623 \mathrm{~mm})$ in 2001.

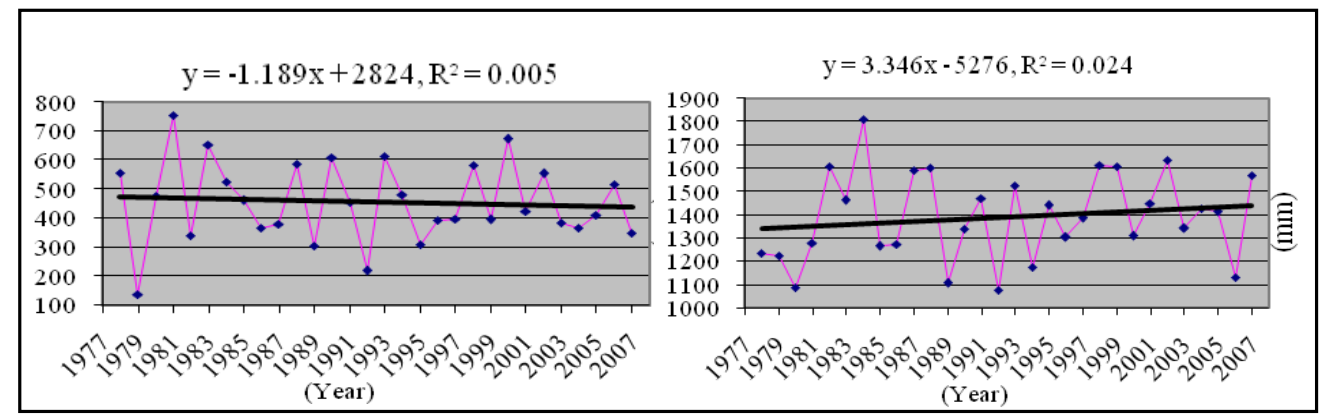

(a)

(b)

Figure 8. Shows total rainfalls in Bangladesh (a) Pre-Monsoon (b) Monsoon.

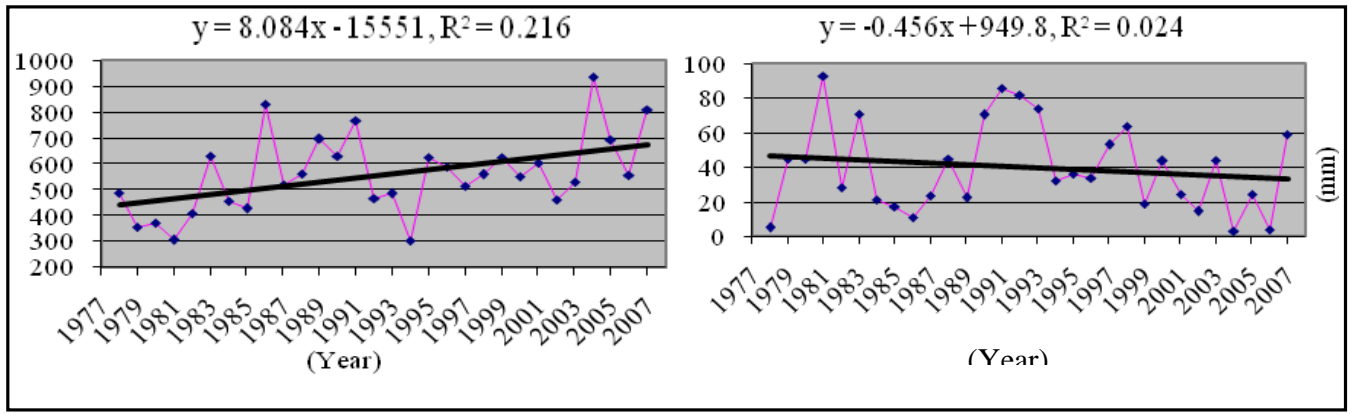

(a)

(b)

Figure 9. Total rainfall in Bangladesh (a) Post-Monsoon and (b) Winter.

Among the last five years (2003-2007), this region received less rainfall in three years (2004, 2005, and 2006) than the 30-year Monsoon average. Though the Monsoon in Sylhet is showing an increasing 
trend in total rainfall (4.117 mm/year), Pre-Monsoon and Post-Monsoon recorded negative trends, and, in Winter, the trend is almost flat. In year-based analysis, rainfall pattern in this region showed a decreasing trend, at a rate of $6.252 \mathrm{~mm} /$ year with an average rainfall at about $4073( \pm 598) \mathrm{mm} /$ year.

Among the four regions (Rajshahi, Barisal, Chittagong and Sylhet), only Chittagong showed an increasing trend in rainfall in the Winter season. In Post-Monsoon, a decreasing trend in rainfall is observed only in the Sylhet region. Analysis showed that in both Pre-Monsoon and Monsoon seasons, rainfall is increasing in Rajshahi and decreasing in Barisal.

\subsection{Temperature-Rainfall Inter-Linkage}

Temperature and rainfall are the most prominent parameters in climate study. With global climate change, temperature and rainfall are changing their pattern and spatial distribution. This present research finds a significant linkage between temperature and rainfall in Pre-Monsoon and Winter seasons of Bangladesh. However, in Monsoon and Post-Monsoon, the relationship was found to be insignificant (Table 1).

Table 1. Interrelation between temperature and rainfall in different seasons in Bangladesh.

\begin{tabular}{|c|c|c|c|c|c|}
\hline Variables & Season & Constant A & Slope $\beta$ & $\begin{array}{l}\text { Level of } \\
\text { Significance }\end{array}$ & $\begin{array}{c}\text { Model R } \\
\text { Square }\end{array}$ \\
\hline & Pre-Mon & 9139 & -170 & 0.001 & 0.519 \\
\hline \multirow[t]{2}{*}{ Dependent: Total Seasonal Rainfall (mm) } & Post-Mon & 2665 & -78 & 0.322 & 0.035 \\
\hline & Winter & 394 & -17 & 0.049 & 0.131 \\
\hline \multirow{2}{*}{$\begin{array}{l}\text { Independent: Average Maximum Temperature }\left({ }^{\circ} \mathrm{C}\right) \\
\text { Dependent: Total Seasonal Rainfall }(\mathrm{mm})\end{array}$} & Post-Mon & 5113 & -147 & 0.059 & 0.122 \\
\hline & Winter & 651 & -23 & 0.001 & 0.317 \\
\hline \multirow{3}{*}{$\begin{array}{l}\text { Independent: Average Minimum Temperature }\left({ }^{\circ} \mathrm{C}\right) \\
\text { Dependent: Total Seasonal Rainfall }(\mathrm{mm})\end{array}$} & Pre-Mon & 3315 & -128 & 0.006 & 0.244 \\
\hline & Monsoon & 1249 & 6 & 0.972 & 0.001 \\
\hline & Post-Mon & 737 & -8 & 0.904 & 0.001 \\
\hline
\end{tabular}

For an increase of $1{ }^{\circ} \mathrm{C}$, the average maximum temperature in Pre-Monsoon rainfall will decrease by $153 \mathrm{~mm}$. Similarly, a $1{ }^{\circ} \mathrm{C}$ increase in average maximum temperature may cause a decrease of $23 \mathrm{~mm}$ in rainfall in Winter season. For average minimum temperature, an increase of $1^{\circ} \mathrm{C}$ may reduce by $127 \mathrm{~mm}$ in rainfall in the Pre-Monsoon season. Similarly, for seasonal average temperature, an increase of $1{ }^{\circ} \mathrm{C}$ may cause a decrease of $170 \mathrm{~mm}$ rainfall in Pre-Monsoon and $17 \mathrm{~mm}$ in Winter season.

\section{Discussion}

The geospatial modeling results revealed that the northeastern Sylhet region has clearly shown a discontinuity in the Monsoon progression (southeast to northwest) across Bangladesh. On the contrary, the northeast region compared to the usual Monsoon progression from the southeast to the northwest showed a peculiar early onset. This peculiarity in Monsoon in the northeast region has also been reported [44,45]. Reference [46] has also postulated that this peculiar early onset clearly depicts a smaller scale location specific Monsoon mechanism that influences the rain and climate in northeast Bangladesh. This less understood location specific micro climate process could be attributed to the region's close proximity to highly complex topography of the Himalayan mountain system, where the height of mountaintops changes by about $2000 \mathrm{~m}$ over a distance of less than $50 \mathrm{~km}$ [45]. This abrupt change in topography creates Monsoons through northeast Bangladesh and adjacent India. This strength of the Mann-Kendall test in finding the seasonal and locational processes in geospatial pattern of climate parameters were also shown by [47] and [48]. Please see Section 2.3.2 for further deliberation on these. 
Several previous studies have shown trends of climate change in climatic parameters over Bangladesh. Chowdhury and Debsharma [6] and Mia [7] found out that temperature has been increasing using historical data of some selected meteorological stations. Reference [7] and [8] reported that mean annual temperature of Bangladesh has increased during the period of $1895-1980$ at $0.31{ }^{\circ} \mathrm{C}$ over the past two decades, and the trends show a close match to the findings of this research. Karmakar and Shrestha [10] projected that annual mean maximum temperature will increase to $0.4{ }^{\circ} \mathrm{C}$ and $0.73{ }^{\circ} \mathrm{C}$ by the year of 2050 and 2100, respectively. The differences in trends could be attributed to different time periods used by different research and approaches as well.

The Mann-Kendall test showed significant linkage between temperature and rainfall in Pre-Monsoon and Winter seasons, which is substantiated by the studies in $[3,46,49,50]$. The southeastern region, which is one the most important forest ecosystem zone in the country is experiencing early onset and withdrawal of rain, yet increasing trends in total rainfall except in the Monsoon season [30]. This means that the region is experiencing a lower number of rainy days. However, total rainfall has not changed significantly. This changing pattern in average maximum and minimum temperature along with precipitation might cause a situation in which the species which are growing now may shift to suitable habitats elsewhere in the future [51].

\section{Conclusions}

The geospatial modeling and perception survey results from Sylhet clearly show a discontinuity in the Monsoon progression (southeast to northwest) across Bangladesh. This divergence of Monsoon progression and a peculiar early onset in the northeast region implies that there is a smaller scale Monsoon mechanism influencing the rain and climate in northeast Bangladesh, and this is peculiar and less understood. Understanding this small mechanism is important for better analysis of GCM (Global Circulation/Climate Model) and RAM (Regional Atmospheric Model) results. For example, if these climate models do not resolve these small mechanisms, early Monsoon onset in this region, RAM/RCM (Regional Climate Model) may give results that will be difficult to explain. Understanding the micro process is also important because it would have direct implication on the tropical ecosystem with rich forests and wetland habitats. More importantly, the region has been historically gifted with the highest amount of rainfall in Bangladesh. These climatic conditions are imperative for sustainable tea production, which is one of the major industries and employment sources. In addition, the model scenarios for the eastern part of the country, much of which is a hilly and coastal region, experienced the impacts of warming all the year round, which is here further substantiated by these findings from a community level perception survey. The region is experiencing early onset and withdrawal of rain, yet increasing trends in total rainfall except in the Monsoon season. This means the region is experiencing fewer numbers of rainy days. However, total rainfall has not changed significantly. This implies that at the beginning of the Monsoon, the region is experiencing more rainfall and hence flooding, which may be associated with some accompanying landslides in the region. In addition to that incremental gap between Tmax and Tmin, temperatures may appear as inhibiting factors for germination and natural propagation of different plant species in the southeast region of Bangladesh. The impact of this changing climate would be varied on NPP (Net Primary Production) according to vegetation types.

Acknowledgments: We acknowledge S.M. Tanvir Hasan, Shariful Islam and Bakul Mia at the Bangladesh Centre for Advanced Studies (BCAS) in assisting with GIS analysis, and Nabir Mamnun and Golam Maainuddin who were involved in the data collection, in particular. Special thanks also go to Atiq Rahman for his guidance and advice. This work was funded by the Norwegian Ministry of Foreign Affairs under a collaborative project "Institutional Support and Capacity Building for Studies of, and Adapting to, Climate Change in Bangladesh" between the BCAS and the Bjerknes Centre for Climate Research (BCCR), Uni Research, Bergen, Norway.

Author Contributions: All the research work was conducted by the first author with the supervision of the second author. The first author conceived and developed the research idea and conceptual framework, and designed the experiments, performed the experiments and analyzed the data with guidance from second author. The first author wrote the paper with valuable input and guidance from second author.

Conflicts of Interest: The authors declare no conflict of interest. 


\section{References}

1. Bangladesh National Committee of ICID (BANCID). National Minor Irrigation Census Report; BANCID: Dhaka, Bengal, 1998.

2. Blanford Henry, F. On the connexion of the Himalaya snowfall with dry winds and seasons of drought in India. Proc. R. Soc. Lond. 1884, 37, 3-22. [CrossRef]

3. Ashfaq, M.; Shi, Y.; Tung, W.; Robert, J.; Xueijie, T.; Gao, J.; Pal, S.; Noah, S. Diffenbaugh. Suppression of south Asian summer Monsoon precipitation in the 21st century. Geophys. Res. Lett. 2009, 36, L01704. [CrossRef]

4. Harmeling, S. Global Climate Risk Index-2012. Bonn: Germanwatche V. Available online: http:/ / www.germanwatch.org/klima/cri2011.pdf (accessed on 6 June 2012).

5. Singh, D.; Tsiang, M.; Rajaratnam, B.; Dienbaugh, N.S. Observed changes in extreme wet and dry spells during the South Asian summer Monsoon season. Nat. Clim. Chang. 2014. [CrossRef]

6. Chowdhury, M.H.K.; Debsharma, S.K. Climate change in Bangladesh-A statistical review. In Proceedings of the IOC-UNEP Workshop on Impacts of Sea Level Rise due to Global Warming, Divya, Bangladesh, 16-19 November 1992.

7. Mia, N.M. Variations of temperature of Bangladesh. In Proceedings of SAARC Seminars on Climate Variability in the South Asian Region and its Impacts, Dhaka, Bangladesh, 10-12 December 2003.

8. Parthasarathy, B.; Sontake, N.A.; Monot, A.A.; Kothawale, D.R. Drought-flood in the summer Monsoon season over different meteorological subdivisions of India for the period 1871-1984. J. Climatol. 1987, 7 , 57-70. [CrossRef]

9. Mehrotra, D.; Mehrotra, R. Climate change and hydrology with emphasis on the Indian subcontinent. Hydrol. Sci. J. 1995, 2, 231-242. [CrossRef]

10. Karmakar, S.; Shrestha, M.L. Recent Climate Change in Bangladesh; SMRC No.4; SMRC: Dhaka, Bangladesh, 2000.

11. Hossain, M.; Islam, A.T.M.A.; Saha, S.K. Floods in Bangladesh-An analysis of their nature and causes. In Floods in Bangladesh Recurrent Disaster and People's Survival; Universities Research Centre: Dhaka, Bangladesh, 1987; pp. 1-21.

12. Rafiuddin, M.; Uyeda, H.; Islam, M.N. Simulation of characteristics of precipitation systems developed in Bangladesh during pre-monsoon and monsoon. In Proceedings of the 2nd International Conference on Water and Flood Management, Dhaka, Bangladesh, 15-17 March 2009; Institute of Water and Flood Management, BUET: Dhaka, Bangladesh, 2009; pp. 61-68.

13. Smith, J.B.; Rahman, A.; Mirza, M.Q. Considering Adaptation to Climate Change in the Sustainable Development of Bangladesh; The World Bank by Stratus Consulting Inc.: Boulder, CO, USA, 1998.

14. MPO. National Water Management Plan: Phase II, Final Report, Master Planning Organization (MPO), Ministry of Irrigation, Water Development and Flood Control; Government of the People's Republic of Bangladesh: Dhaka, Bangladesh, 1991.

15. Chiew, F.H.S. Estimation of rainfall elasticity of stream flow in Australia. Hydrol. Sci. J. 2006, 51, $613-625$. [CrossRef]

16. Shin, H.H.; Hong, S.Y. Intercomparison of Planetary Boundary-Layer Parametrizations in the WRF Model for a Single Day from CASES-99. Bound. Layer Meteorol. 2011, 139, 261-281. [CrossRef]

17. IPCC; Rosenzweig, C.; Casassa, G.; Imeson, A.; Karoly, D.J.; Liu Chunzhen, M.A.; Rawlins, S.; Root, T.L.; Seguin, B.; Tryjanowski, P. Assessment of Observed Changes And Responses in Natural and Managed Systems. Available online: http://www.ipcc.ch/pdf/assessment-report/ar4/wg2/ar4-wg2-chapter1.pdf (accessed on 8 January 2008).

18. Arfanuzzaman, M.; Mamnun, N.; Islam, M.S.; Dilshad, T.; Syed, M.A. Evaluation of Adaptation Practices in the Agriculture Sector of Bangladesh: An Ecosystem Based Assessment. Climate 2016, 4. [CrossRef]

19. Syed, M.A. Regional analysis, import-export and related issues on food security. In Food Security and Risk Reduction in Bangladesh; Umma, H., Anwarul, A., Abu Wali, R.H., Rajib, S., Eds.; Springer: Tokyo, Japan, 2015; pp. 111-134.

20. Rauscher, S.A.; Coppola, E.; Piani, C.; Giorgi, F. Resolution effects on regional climate model simulations of seasonal precipitation over Europe. Part I: Seasonal. Clim. Dyn. 2010, 35, 685-711. [CrossRef]

21. Rashid, H.E. Geography of Bangladesh, 2nd ed.; The University Press Ltd.: Dhaka, Bangladesh, 1991. 
22. Huq, S.; Asaduzzaman, M. Overview. In Vulnerability and Adaptation to Climate Change for Bangladesh; Huq, S., Karim, Z., Asaduzzaman, M., Mahtab, F., Eds.; Kluwer Academic Publishers: Dordrecht, The Netherlands, 1999; pp. 1-11.

23. Armstrong, J.S. Illusions in regression analysis. Int. J. Forecast. 2012. [CrossRef]

24. Freedman, D.A. Statistical Models: Theory and Practice; Cambridge University Press: Cambridge, UK, 2005.

25. Cook, R.D.; Weisberg, S. Criticism and influence analysis in regression. Sociol. Methodol. 1982, 13, $313-361$. [CrossRef]

26. Mann, H.B. Non-parametric test against trend. Econometrica 1945, 13, 245-259. [CrossRef]

27. Kendall, M.G. Rank Correlation Methods, 4th ed.; Charles Griffin: London, UK, 1975.

28. Dietz, E.J.; Killeen, T.J. A nonparametric multivariate test for monotone trend with pharmaceutical applications. J. Am. Stat. Assoc. 1981, 76, 169-174. [CrossRef]

29. Hirsch, R.M.; Slack, J.R. A nonparametric trend test for seasonal data with serial dependence. Water Resour. Res. 1984, 20, 727-732. [CrossRef]

30. Lettenmaier, D.P. Multivariate nonparametric tests for trend in water quality. Water Resour. Bull. 1988, 24, 505-512. [CrossRef]

31. Libiseller, C.; Grimvall, A. Performance of Partial Mann Kendall Tests for Trend Detection in the Presence of Covariates. Environmetrics 2002, 13, 71-84. [CrossRef]

32. Shahid, S. Trends in extreme rainfall events of Bangladesh. Theor. Appl. Climatol. 2011, 104, 489-499. [CrossRef]

33. Gilbert, R.O. Statistical Methods for Environmental Pollution Monitoring; Van Nostrand Reinhold Co.: New York, NY, USA, 1987.

34. Salmi, T.; Maata, A.; Antilla, P.; Ruoho-Airola, T.; Amnell, T. Detecting Trends of Annual Values of Atmospheric Pollutants by the Mann-Kendall Test and Sen's Slope Estimates-The Excel Template Application Makesens; Finnish Meteorological Institute: Helsinki, Finland, 2002.

35. Luo, Y.; Liu, S.; Fu, S.F.; Liu, J.; Wang, G.; Zhou, G. Trends of precipitation in Beijiang River Basin, Guangdong Province, China. Hydrol. Process. 2008, 22, 2377-2386. [CrossRef]

36. Reeve, M.A.; Syed, M.D.; Hossain, P.R.; Maainuddin, G.; Mamnun, N. Community level perceptions of the monsoon onset, withdrawal and climatic trends in Bangladesh, Theme: Prediction and predictability of the monsoon, extended abstract. In Proceedings of the International Conference on Opportunities and Challenges in Monsoon Prediction in a Changing Climate (OCHAMP-2012), Pune, India, 21-25 February 2012; pp. 21-25.

37. Marqunez, J.; Lastra, J.; Garcia, P. Estimation models for precipitation in mountainous regions: The use of GIS and multivariate analysis. J. Hydrol. 2003, 270, 1-11. [CrossRef]

38. Phillips, D.L.; Dolph, J.; Mark, D. A Comparison of geostatistical procedures for spatial analysis of precipitation in mountainous terrain. Agric. For. Meteorol. 1992, 58, 119-141. [CrossRef]

39. Creutin, J.O.C. Objective Analyses and mapping techniques for rainfall fields: An objective comparison. Water Resour. Bull. 1982, 18, 413-431. [CrossRef]

40. Tabios, G.Q.; Salas, J.D. Comparative analysis of techniques for spatial interpolation of precipitation. Water Resour. Bull. 1985, 21, 365-380. [CrossRef]

41. Landau, S.; Barnett, V. A comparison of methods for climate data interpolation, in the context of yield predictions from Winter wheat simulation models. Aspects Biol. 1996, 46, 13-22.

42. Cornford, D. The Development and Application of Techniques for Mapping Daily Minimum Air Temperatures. Ph.D. Thesis, University of Birmingham, Birmingham, UK, 1997.

43. Lennon, J.J.; Turner, J.R.G. Predicting the spatial distribution of climate: Temperature in Great Britain. J. Anim. Ecol. 1995, 64, 370-392. [CrossRef]

44. Jarvis, C.C.; Stuart, N. A Comparison among Strategies for Interpolating Maximum and Minimum Daily Air Temperatures. Part II: The Interaction between Number of Guiding Variables and the Type of Interpolation Method. Am. Meteorol. Soc. 2001, 40, 1075-1084. [CrossRef]

45. Bolstad, P.V.; Swift, L.; Collins, F.; Regniere, J. Measured and predicted air temperatures at basin to regional scales in the southern Appalachian Mountains. Agric. For. Meteorol. 1998, 91, 161-178. [CrossRef]

46. Tomislav, H.; Geuvelink, G.B.M.; Stein, A. Comparison of Krigging with External Drift and Regression-Krigging, Technical Note, 2003, ITC. Available online: https://www.itc.nl/library/Papers _2003/misca/hengl_comparison.pdf (accessed on 5 April 2016). 
47. Ahmed, R.; Karmakar, S. Arrival and withdrawal dates of the summer monsoon in Bangladesh. Int. J. Climatol. 1993, 13, 727-740. [CrossRef]

48. Kumar, R.; Anil, D.; Bhowmik, S.K.R. Evaluation of physics options of the Weather Research and Forecasting (WRF) Model to simulate high impact heavy rainfall events over Indian Monsoon region. GEOFIZIKA 2010, 27, 101-125.

49. Murata, F.; Terao, T.; Kiguchi, M.; Fukushima, A.; Takahashi, K.; Hayashi, T.; Habib, A.; Bhuiyan, M.S.; Choudhury, S.A. Daytime thermodynamic and airflow structures over Northeast Bangladesh during the pre-monsoon season: A Case Study on 25 April 2010. J. Meteorol. Soc. Jpn. 2011, 89, 167-179. [CrossRef]

50. Mondal, A.; Kundu1, S.; Mukhopadhyay, A. Rainfall trend analysis by Mann-Kendall test: A case study of North-Eastern part of Cuttack district, Orissa. Int. J. Geol. Earth Environ. Sci. 2012, 2, 70-78.

51. Allen, C.D.; Macalady, A.K.; Chenchouni, H.; Bachelet, D.; McDowell, N.; Vennetier, M.; Kitzberger, T.; Rigling, A.; Breshears, D.D.; Hogg, E.H.; et al. A global overview of drought and heat-induced tree mortality reveals emerging climate change risks for forests. For. Ecol. Manag. 2010, 259, 660-684. [CrossRef]

(C) 2016 by the authors; licensee MDPI, Basel, Switzerland. This article is an open access article distributed under the terms and conditions of the Creative Commons Attribution (CC-BY) license (http://creativecommons.org/licenses/by/4.0/). 